Cite this: RSC Adv., 2013, 3, 24983

Received 3rd October 2013 Accepted 11th October 2013

DOI: $10.1039 / \mathrm{c} 3 \mathrm{ra} 45541 f$

www.rsc.org/advances

\title{
RAFT polymerization of fatty acid containing monomers: controlled synthesis of polymers from renewable resources $\dagger$
}

\author{
Binoy Maiti and Priyadarsi De* \\ The incorporation of bio-renewable resources such as fatty acids into the polymer chain allows tailoring the \\ properties of products, for their widespread applications. A series of methacrylate monomers with side- \\ chain fatty acids (FAMA) were synthesized by esterification of 2-hydroxyethyl methacrylate (HEMA) and \\ fatty acids, such as caprylic, capric, lauric, mysritic, palmitic and stearic acid. Consequent polymerization \\ of FAMAs via reversible addition-fragmentation chain transfer (RAFT) gave side-chain fatty acid- \\ containing well-defined polymers (PFAMA) with targeted molecular weights, narrow molecular weight \\ distribution and precise chain-end functionality. The PFAMAs were subsequently used as macro-chain \\ transfer agents (macro-CTA) for the polymerization of 2-(2-methoxyethoxy)ethyl methacrylate \\ $\left(\mathrm{MEO}_{2} \mathrm{MA}\right)$ to obtain block copolymers. Homopolymers with fatty acid pendants display crystalline \\ behaviour depending on the chain length of the fatty acids, evidenced by differential scanning \\ calorimetry (DSC), polarized optical microscopy, small-angle X-ray scattering (SAXS) and wide-angle \\ $\mathrm{X}$-ray scattering (WAXS) techniques.
}

\section{Introduction}

The use of renewable resources in various applications is receiving growing attention from both industry and academia. ${ }^{1}$ Fatty acids (FA) and their derivatives are important bio-renewable resources, they are readily available, inexpensive, biocompatible and find numerous applications in diverse fields. ${ }^{2}$ Fatty acid derivatives have been used in the area of macromolecular science for a long period of time for the synthesis of varieties of monomers as well as linear and cross-linked polymers of different types (e.g. polyolefins, polyesters, polyethers, polyamides, epoxy and polyurethane resins, and others) via stepgrowth polymerization mechanism..$^{3,4}$ Recent progresses on the preparation of vegetable oil-based thermoplastic polyesters and polyurethanes have been reviewed. ${ }^{5}$

Although long-chain alkyl methacrylates show side-chain crystallinity having side chains with 12 carbon atoms or longer, ${ }^{6}$ only lauryl methacrylate (LMA) has been polymerized by atom transfer radical polymerization (ATRP), ${ }^{7}$ which is a controlled/living radical polymerization (CRP) ${ }^{8}$ technique. Recently, Çayli and Meier polymerized fatty acid containing methacrylates using ATRP to prepare FA based polymers with targeted molecular weights, narrow polydispersity index (PDI) and specific chain end structures. ${ }^{9}$

Polymer Research Centre, Department of Chemical Sciences, Indian Institute of Science Education and Research-Kolkata, PO: BCKV Campus, Nadia, Mohanpur - 741252, India.E-mail: p_de@iiserkol.ac.in

$\dagger$ Electronic supplementary information (ESI) available: Synthesis procedures and material characterizations. See DOI: $10.1039 / \mathrm{c} 3 \mathrm{ra} 45541 \mathrm{f}$
The RAFT polymerization is the most versatile CRP technique compared to the other CRP methods (ATRP and nitroxidemediated radical polymerization), and RAFT technique is applicable to a wide range of monomers, initiator functionality, solvents and temperatures. ${ }^{10}$ Also, RAFT made polymers are better candidates for biological and pharmaceutical applications compared to ATRP generated macromolecules. ${ }^{11}$ Alkylmacro-RAFT agents have been used to prepare acrylic and coacrylic-alkyd block copolymers via RAFT technique. ${ }^{12}$ Recently, sustainable thermoplastic elastomers derived from fatty acids have been reported using RAFT method..$^{13}$ Among the various FA's, only the LMA have been polymerized by RAFT. ${ }^{14}$ Herein, we report the systematic RAFT polymerization of various fatty acid derived monomers in the presence of a free radical initiator $2,2^{\prime}$-azobisisobutyronitrile (AIBN) at $70{ }^{\circ} \mathrm{C}$ in tetrahydrofuran (THF) and 4-cyano-4-(dodecylsulfanylthiocarbonyl)sulfanylpentanoic acid (CDP) as the chain transfer agent (CTA) (Scheme 1). By adjusting the chain lengths of the fatty acids, polymers exhibit crystallinity. Polymer crystallinity is important since crystallinity affects their physical and mechanical properties such as storage modulus, permeability, density, stiffness, melting point, etc.

\section{Experimental section}

\section{Materials}

Fatty acids such as caprylic acid (CLA, $\geq 98 \%$ ), capric acid (CRA, $\geq 98 \%$ ), lauric acid (LA, 98\%), mysritic acid (MA, $\geq 99 \%$ ), palmitic acid (PA, $\geq 99 \%$ ) and stearic acid (SA, $\geq 95 \%$ ) were 


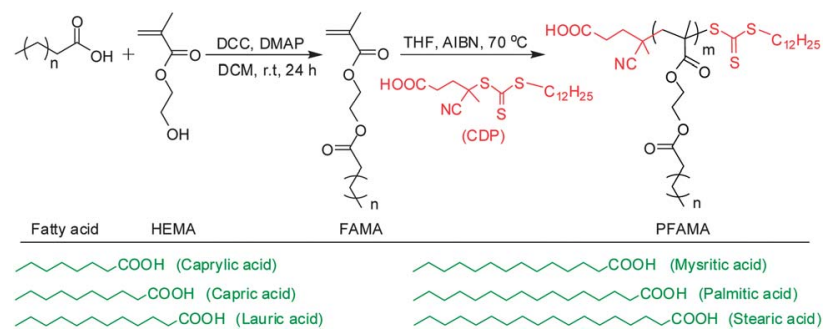

Scheme 1 Synthesis protocol for side-chain fatty acid containing methacrylate polymers by RAFT polymerization

purchased from Sigma-Aldrich and used as received. 2-Hydroxyethyl methacrylate (HEMA, 97\%), dicyclohexylcarbodiimide (DCC, 99\%), 4-dimethylaminopyridine (DMAP, 99\%), and anhydrous $N, N$-dimethylformamide (DMF, 99.9\%) were purchased from Sigma and used without any further purification. Poly(ethylene glycol) methyl ether methacrylate $\left(\mathrm{MEO}_{2} \mathrm{MA}, M_{\mathrm{n}}=300 \mathrm{~g} \mathrm{~mol}^{-1}\right.$, Aldrich, $\left.99 \%\right)$ was passed through a basic alumina column prior to polymerization. The 4-cyano-4(thiobenzylthio)pentanoic acid (СTP) ${ }^{15}$ and 4-cyano-(dodecylsulfanylthiocarbonyl)sulfanylpentanoic acid $(\mathrm{CDP})^{\mathbf{1 6}}$ were synthesized following the standard literature procedure mentioned elsewhere. $\mathrm{CDCl}_{3}(99.8 \% \mathrm{D})$ was obtained from Cambridge Isotope Laboratories, Inc, USA for NMR study. The solvents dichloromethane (DCM), THF, methanol (MeOH), ethyl acetate (EtOAc) and hexanes were purified by following general procedure.

\section{Instrumentation}

Gel permeation chromatography (GPC) was used to obtain molecular weights and molecular weight distributions (polydispersity index, PDI) of polymers and the GPC instrument contains a Waters 515 HPLC pump, a Waters 2414 refractive index (RI) detector and two columns (Styragel HT4 and Styragel HT3) in THF at $30{ }^{\circ} \mathrm{C}$ at $1.0 \mathrm{~mL} \mathrm{~min}{ }^{-1}$ flow rate. The instrument was calibrated by using poly(methyl methacrylate) (PMMA) standards. The ${ }^{1} \mathrm{H}$ NMR spectra were acquired in a Bruker Avance ${ }^{\mathrm{III}} 500$ spectrometer operating at $500 \mathrm{MHz}$. Positive mode electrospray ionization mass spectrometry (ESI-MS) was performed on a Q-Tof Micro YA263 high resolution (Waters Corporation) mass spectrometer. The UV-Vis spectroscopic study was carried out using a Perkin-Elmer Lambda 35 UV-Vis spectrophotometer. Rigaku Smart Lab powder diffractometer having $\mathrm{Cu} \mathrm{K} \alpha=1.54059 \AA$ radiation was used for recording X-ray diffraction (XRD) spectra. Polarized optical microscopic studies were carried out using an Olympus $\mathrm{CH} 30$ imaging microscope equipped with Image Pro Plus version 4.0 Software. Differential scanning calorimetric (DSC) studies were performed on a Mettler Toledo DSC1 STARe at $10{ }^{\circ} \mathrm{C} \mathrm{min}{ }^{-1}$. Polymers were first cooled from room temperature to $-70{ }^{\circ} \mathrm{C}$, then heated to $+120{ }^{\circ} \mathrm{C}$ and again cooled to $-70{ }^{\circ} \mathrm{C}$ at $10{ }^{\circ} \mathrm{C} \mathrm{min}{ }^{-1}$. The crystalline melting temperature $\left(T_{\mathrm{m}}\right)$ was taken from the third segment of the run i.e. from +120 to $-70{ }^{\circ} \mathrm{C}$, as the solvent or other volatile impurities would have evaporated on heating from -70 to $120{ }^{\circ} \mathrm{C}$.
The thermogravimetric analysis (TGA) was performed on a Mettler Toledo TGA/SDTA 851e instrument at a heating rate of $10{ }^{\circ} \mathrm{C} \min ^{-1}$ in $\mathrm{N}_{2}$ atmosphere.

\section{Synthesis of FAMA monomers}

The monomers from various fatty acids (FAMA), such as caprylic (CLAMA), capric (CRAMA), lauric (LAMA), mysritic (MAMA), palmitic (PAMA) and stearic (SAMA) were synthesized as follows. In a typical example, CLA $(0.104 \mathrm{~mol}, 15.0 \mathrm{~g})$ and DMAP $(0.0104 \mathrm{~mol}, 1.27 \mathrm{~g})$ were dissolved in $50 \mathrm{~mL}$ dry DCM in a 250 $\mathrm{mL}$ double neck round bottom (RB) flask equipped with a magnetic stir bar. The RB flask was kept on ice-water bath and dry $\mathrm{N}_{2}$ gas was purged through it. In a separate vessel DCC $(0.1144 \mathrm{~mol}, 23.60 \mathrm{~g})$ was dissolved in minimum volume of DCM and was added to the reaction mixture. Then, HEMA $(0.1040 \mathrm{~mol}, 13.53 \mathrm{~g})$ was added drop-wise for $30 \mathrm{~min}$. The icewater bath was removed after $30 \mathrm{~min}$ and the resulting mixture was stirred for $24 \mathrm{~h}$ at room temperature. After $24 \mathrm{~h}$, the reaction mixture was filtered and $80 \mathrm{~mL}$ distilled water was added to the filtrate. The organic layer was further washed with saturated $\mathrm{NaHCO}_{3}(120 \mathrm{~mL} \times 4)$ followed by brine solution $(100 \mathrm{~mL} \times 2)$ and dried over anhydrous $\mathrm{Na}_{2} \mathrm{SO}_{4}$. The solvent was removed by rotary evaporator and purified by column chromatography using silica gel as stationary phase and hexanes-EtOAc $(95: 5$, $\mathrm{v} / \mathrm{v}$ ) as an eluent to obtain CLAMA (yield: $75 \%$ ). ${ }^{1} \mathrm{H}$ NMR (Fig. $\mathrm{S} 1, \dagger 500 \mathrm{MHz}, \mathrm{CDCl}_{3}$, TMS): $\delta(\mathrm{ppm})=6.12$ and $5.58(\mathrm{C}=$ $\left.\mathrm{CH}_{2}, 2 \mathrm{H}, \mathrm{d}\right), 4.32\left(\mathrm{OCH}_{2} \mathrm{CH}_{2} \mathrm{O}, 4 \mathrm{H}, \mathrm{t}\right), 2.32\left(\mathrm{O}=\mathrm{CCH}_{2}, 2 \mathrm{H}, \mathrm{t}\right), 1.61$ $\left(\mathrm{O}=\mathrm{CCH}_{2} \mathrm{CH}_{2}, 2 \mathrm{H}, \mathrm{m}\right), 1.28\left(-\mathrm{CH}_{2} \mathrm{CH}_{2} \mathrm{CH}_{2} \mathrm{CH}_{2}-, 8 \mathrm{H}, \mathrm{m}\right), 1.94$ $\left(\mathrm{CH}_{2}=\mathrm{CCH}_{3}, 3 \mathrm{H}, \mathrm{s}\right), 0.87\left(-\mathrm{CH}_{2} \mathrm{CH}_{3}, 3 \mathrm{H}, \mathrm{t}\right)$; ESI-MS (Fig. S2 $\left.\dagger\right)$ of CLAMA: calculated $m / z$ for $\left[\mathrm{M}+\mathrm{Na}^{+}\right]$: 279.167, observed 279.323.

Similarly, CRAMA, LAMA, MAMA, PAMA and SAMA were synthesized by following the above procedure (Table S1 $\dagger$ ). CRAMA (yield: $76 \%$ ); ${ }^{1} \mathrm{H}$ NMR (Fig. $\mathrm{S} 3, \dagger 500 \mathrm{MHz}, \mathrm{CDCl}_{3}, \mathrm{TMS}$ ): $\delta(\mathrm{ppm})=6.13$ and $5.57\left(\mathrm{C}=\mathrm{CH}_{2}, 2 \mathrm{H}, \mathrm{d}\right), 4.33\left(\mathrm{OCH}_{2} \mathrm{CH}_{2} \mathrm{O}, 4 \mathrm{H}\right.$, $\mathrm{t}), 2.32\left(\mathrm{O}=\mathrm{CCH}_{2}, 2 \mathrm{H}, \mathrm{t}\right), 1.61\left(\mathrm{O}=\mathrm{CCH}_{2} \mathrm{CH}_{2}, 2 \mathrm{H}, \mathrm{m}\right), 1.28$ $\left(-\mathrm{CH}_{2} \mathrm{CH}_{2} \mathrm{CH}_{2} \mathrm{CH}_{2} \mathrm{CH}_{2} \mathrm{CH}_{2}-, 12 \mathrm{H}, \mathrm{m}\right), 1.94\left(\mathrm{CH}_{2}=\mathrm{CCH}_{3}, 3 \mathrm{H}, \mathrm{s}\right)$, $0.88\left(-\mathrm{CH}_{2} \mathrm{CH}_{3}, 3 \mathrm{H}, \mathrm{t}\right)$; ESI-MS (Fig. S4 $\left.\dagger\right)$ of CRAMA: calculated $m / z$ for $\left[\mathrm{M}+\mathrm{Na}^{+}\right]: 307.20$, observed $m / z=307.288$.

LAMA (yield: $80 \%$ ); ${ }^{1} \mathrm{H}$ NMR (Fig. $\mathrm{S} 5, \dagger 500 \mathrm{MHz}, \mathrm{CDCl}_{3}$, TMS $): \delta(\mathrm{ppm})=6.12$ and $5.58\left(\mathrm{C}=\mathrm{CH}_{2}, 2 \mathrm{H}, \mathrm{d}\right), 4.32\left(\mathrm{OCH}_{2}\right.$ $\left.\mathrm{CH}_{2} \mathrm{O}, 4 \mathrm{H}, \mathrm{t}\right), 2.32\left(\mathrm{O}=\mathrm{CCH}_{2}, 2 \mathrm{H}, \mathrm{t}\right), 1.60\left(\mathrm{O}=\mathrm{CCH}_{2} \mathrm{CH}_{2}, 2 \mathrm{H}, \mathrm{m}\right)$, $1.28\left(-\mathrm{CH}_{2} \mathrm{CH}_{2} \mathrm{CH}_{2} \mathrm{CH}_{2} \mathrm{CH}_{2} \mathrm{CH}_{2} \mathrm{CH}_{2} \mathrm{CH}_{2},, 16 \mathrm{H}, \mathrm{m}\right), 1.94\left(\mathrm{CH}_{2}=\right.$ $\left.\mathrm{CCH}_{3}, 3 \mathrm{H}, \mathrm{s}\right), 0.87\left(-\mathrm{CH}_{2} \mathrm{CH}_{3}, 3 \mathrm{H}, \mathrm{t}\right)$; ESI-MS (Fig. S6 $\left.{ }^{\dagger}\right)$ of LAMA: calculated $m / z$ for $\left[\mathrm{M}+\mathrm{Na}^{+}\right]: 335.23$, observed $m / z=335.267$.

MAMA (yield: $85 \%$ ); ${ }^{1} \mathrm{H}$ NMR (Fig. $\mathrm{S} 7, \dagger 500 \mathrm{MHz}, \mathrm{CDCl}_{3}$, TMS): $\delta(\mathrm{ppm})=6.12$ and $5.59\left(\mathrm{C}=\mathrm{CH}_{2}, 2 \mathrm{H}, \mathrm{d}\right), 4.28\left(\mathrm{OCH}_{2-}\right.$ $\left.\mathrm{CH}_{2} \mathrm{O}, 4 \mathrm{H}, \mathrm{t}\right), 2.32\left(\mathrm{O}=\mathrm{CCH}_{2}, 2 \mathrm{H}, \mathrm{t}\right), 1.60\left(\mathrm{O}=\mathrm{CCH}_{2} \mathrm{CH}_{2}, 2 \mathrm{H}, \mathrm{m}\right)$, $1.27\left(-\mathrm{CH}_{2} \mathrm{CH}_{2} \mathrm{CH}_{2} \mathrm{CH}_{2} \mathrm{CH}_{2} \mathrm{CH}_{2} \mathrm{CH}_{2} \mathrm{CH}_{2} \mathrm{CH}_{2} \mathrm{CH}_{2}-, 20 \mathrm{H}, \mathrm{m}\right), 1.94$ $\left(\mathrm{CH}_{2}=\mathrm{CCH}_{3}, 3 \mathrm{H}, \mathrm{s}\right), 0.86\left(-\mathrm{CH}_{2} \mathrm{CH}_{3}, 3 \mathrm{H}, \mathrm{t}\right)$; ESI-MS (Fig. S8 $\left.\dagger\right)$ of MAMA: calculated $m / z$ for $\left[\mathrm{M}+\mathrm{Na}^{+}\right]: 363.26$, observed $m / z=$ 363.28.

PAMA (yield: $77 \%$ ); ${ }^{1} \mathrm{H}$ NMR (Fig. S9, $\dagger 500 \mathrm{MHz}, \mathrm{CDCl}_{3}, \mathrm{TMS}$ ): $\delta(\mathrm{ppm})=6.12$ and $5.59\left(\mathrm{C}=\mathrm{CH}_{2}, 2 \mathrm{H}, \mathrm{d}\right), 4.33\left(\mathrm{OCH}_{2} \mathrm{CH}_{2} \mathrm{O}, 4 \mathrm{H}\right.$, t), $2.32\left(\mathrm{O}=\mathrm{CCH}_{2}, 2 \mathrm{H}, \mathrm{t}\right), 1.61\left(\mathrm{O}=\mathrm{CCH}_{2} \mathrm{CH}_{2}, 2 \mathrm{H}, \mathrm{m}\right), 1.27$ $\left(-\mathrm{CH}_{2} \mathrm{CH}_{2} \mathrm{CH}_{2} \mathrm{CH}_{2} \mathrm{CH}_{2} \mathrm{CH}_{2} \mathrm{CH}_{2} \mathrm{CH}_{2} \mathrm{CH}_{2} \mathrm{CH}_{2} \mathrm{CH}_{2} \mathrm{CH}_{2}-, \quad 24 \mathrm{H}, \mathrm{m}\right)$ $1.94\left(\mathrm{CH}_{2}=\mathrm{CCH}_{3}, 3 \mathrm{H}, \mathrm{s}\right), 0.86\left(-\mathrm{CH}_{2} \mathrm{CH}_{3}, 3 \mathrm{H}, \mathrm{t}\right) ;$ ESI-MS 
(Fig. S10 $\dagger$ ) of PAMA: calculated $m / z$ for $\left[\mathrm{M}+\mathrm{Na}^{+}\right]$: 391.29, observed $\mathrm{m} / \mathrm{z}=391.27$.

SAMA (yield: 74\%); ${ }^{1} \mathrm{H}$ NMR (500 $\left.\mathrm{MHz}, \mathrm{CDCl}_{3}, \mathrm{TMS}\right): \delta$ $(\mathrm{ppm})=6.12$ and $5.59\left(\mathrm{C}=\mathrm{CH}_{2}, 2 \mathrm{H}, \mathrm{d}\right), 4.33\left(\mathrm{OCH}_{2} \mathrm{CH}_{2} \mathrm{O}, 4 \mathrm{H}, \mathrm{t}\right)$, $2.32\left(\mathrm{O}=\mathrm{CCH}_{2}, 2 \mathrm{H}, \mathrm{t}\right), 1.61\left(\mathrm{O}=\mathrm{CCH}_{2} \mathrm{CH}_{2}, 2 \mathrm{H}, \mathrm{m}\right), 1.27$ $\left(-\mathrm{CH}_{2} \mathrm{CH}_{2} \mathrm{CH}_{2} \mathrm{CH}_{2} \mathrm{CH}_{2} \mathrm{CH}_{2} \mathrm{CH}_{2} \mathrm{CH}_{2} \mathrm{CH}_{2} \mathrm{CH}_{2} \mathrm{CH}_{2} \mathrm{CH}_{2} \mathrm{CH}_{2} \mathrm{CH}_{2}^{-}\right.$, $28 \mathrm{H}, \mathrm{m}), 1.94\left(\mathrm{CH}_{2}=\mathrm{CCH}_{3}, 3 \mathrm{H}, \mathrm{s}\right), 0.86\left(-\mathrm{CH}_{2} \mathrm{CH}_{3}, 3 \mathrm{H}, \mathrm{t}\right)$; ESIMS (Fig. S11 $\dagger$ ) of SAMA: calculated $m / z$ for $\left[\mathrm{M}+\mathrm{Na}^{+}\right]$: 419.324, observed $m / z=419.284$.

\section{Synthesis of homopolymers via RAFT polymerization}

In a typical example, CLAMA (0.78 mmol, $0.20 \mathrm{~g})$, CDP (1.56 $\mu \mathrm{mol}, 6.29 \mathrm{mg}$ ), AIBN (3.1 $\mu \mathrm{mol}, 0.51 \mathrm{mg} ; 102 \mathrm{mg}$ solution of $10.0 \mathrm{mg}$ AIBN in $2.0 \mathrm{~g}$ THF) and $0.898 \mathrm{~g}$ THF were added to a 20 $\mathrm{mL}$ septa sealed glass vial equipped with a magnetic bar and purged with dry $\mathrm{N}_{2}$ gas for $15 \mathrm{~min}$. The reaction vial was put in a preheated reaction block at $70{ }^{\circ} \mathrm{C}$ for $7 \mathrm{~h}$. Then, the reaction was quenched by cooling in ice-water bath, purified by reprecipitation in $\mathrm{MeOH}$ at least five times (from acetone solution) and dried under high vacuum at room temperature to obtain yellowish sticky polymer.

\section{Chain extension reactions}

CLAMA $(100.0 \mathrm{mg}, 0.390 \mathrm{mmol})$, PCLAMA macro-CTA $\left(M_{\mathrm{n}, \mathrm{GPC}}=\right.$ $7500 \mathrm{~g} \mathrm{~mol}^{-1}$, PDI = 1.10, $117.0 \mathrm{mg}, 0.0156 \mathrm{mmol}$ ), AIBN (3.1 $\mu \mathrm{mol}, 0.51 \mathrm{mg} ; 102.0 \mathrm{mg}$ solution of $10.0 \mathrm{mg}$ AIBN in $2.0 \mathrm{~g}$ THF) and $0.898 \mathrm{~g}$ THF were added to the $20 \mathrm{~mL}$ polymerization vial equipped with a magnetic stir bar and purged with dry $\mathrm{N}_{2}$ for 15 min. The reaction vial was put in a preheated reaction bath at $70{ }^{\circ} \mathrm{C}$ for $7 \mathrm{~h}$, quenched by cooling in ice-water bath, and purified as mentioned above for the homopolymers.

\section{Synthesis of block copolymers}

$\mathrm{MEO}_{2} \mathrm{MA}$ (0.5 mmol, $\left.150.0 \mathrm{mg}\right)$, PCLAMA macro-CTA $\left(M_{\mathrm{n}, \mathrm{GPC}}=\right.$ $7500 \mathrm{~g} \mathrm{~mol}^{-1}$, PDI $\left.=1.10,0.150 \mathrm{~g}, 0.02 \mathrm{mmol}\right)$, AIBN $(4.0 \mu \mathrm{mol}$, $0.656 \mathrm{mg} ; 132.0 \mathrm{mg}$ solution of $10.0 \mathrm{mg}$ AIBN in $2.0 \mathrm{~g}$ THF), and THF $(0.868 \mathrm{~g})$ were added in a $20 \mathrm{~mL}$ polymerization vial equipped with a magnetic bar and purged with dry $\mathrm{N}_{2}$ gas for 15 min. The reaction vial was put in a preheated reaction block at $70{ }^{\circ} \mathrm{C}$ for $7 \mathrm{~h}$. The reaction was quenched by cooling in ice-water bath and purified by reprecipitation in hexanes at least five times and dried under vacuum at room temperature to obtain yellowish sticky polymer. For PLAMA- $b-\mathrm{PMEO}_{2} \mathrm{MA}$, PMAMA- $b$ $\mathrm{PMEO}_{2} \mathrm{MA}$, PPAMA- $b-\mathrm{PMEO}_{2} \mathrm{MA}$ and PSAMA- $b-\mathrm{PMEO}_{2} \mathrm{MA}$ we used water as a non-solvent and block copolymers were lyophilized.

\section{Results and discussion}

\section{Monomer synthesis}

Side chain FA containing monomers were synthesized by esterification condensation of HEMA and fatty acids in the presence of DCC as coupling agent and DMAP as catalyst in DCM solvent at room temperature for $24 \mathrm{~h}$. The FAMA monomers were obtained in high yields $(74-85 \%$, Table S1 of the ESI $\dagger$ ) and structures were confirmed by ${ }^{1} \mathrm{H}$ NMR and mass spectroscopy. All the proton peaks have been assigned on their NMR spectrum (Fig. 1A for SAMA and more spectra in the $\operatorname{ESI} \dagger$ ). Experimental molecular masses obtained from ESI-MS study matched well with the theoretical molecular mass values (ESIMS spectra in the ESI $\dagger$ ). Also, FT-IR analysis of the monomers showed characteristic ester carbonyl group and the double bond $\mathrm{CH}_{2}=\mathrm{C}\left(\mathrm{CH}_{3}\right)$ - peaks. For example, stretching vibrations of the carbonyl $\mathrm{C}=\mathrm{O}$ group and vinyl double bond in the FT-IR spectrum of CLAMA were observed at 1725 and $1638 \mathrm{~cm}^{-1}$, respectively (figure not shown).

\section{RAFT polymerization}

FAMA's are polymerized by RAFT method at $70^{\circ} \mathrm{C}$ with CDP and AIBN in DMF and THF at [FAMA] : [CDP] : [AIBN] $=50 / 1 / 0.2$. Although all the monomers are soluble in DMF (Table S2, $\mathrm{ESI}_{\dagger} \dagger$ ), polymer from stearic acid (PSAMA) is insoluble in DMF. Polymers from caprylic acid (PCLAMA), capric acid (PCRAMA), lauric acid (PLAMA), mysritic acid (PMAMA) and palmitic acid (PPAMA) are soluble in DMF. Therefore, we obtained low conversion and observed heterogeneous polymerization in DMF for SAMA (Table S3, ESI $\dagger$ ). However, in THF all monomers and polymers are readily soluble and polymerizations proceed with a moderate rate (Table 1$)$. The polymers exhibited narrow PDI $(<1.25)$ and the number average molecular weight $\left(M_{\mathrm{n}, \mathrm{GPC}}\right)$ determined from gel permeation chromatography (GPC) matches well with the theoretical molecular weights $\left(M_{\mathrm{n}, \text { theo }}\right)$ calculated based on monomer conversion. The resulting polymers showed symmetrical GPC peaks without shoulder and tailing (Fig. S12 of the ESI $\dagger$ ). Note that $M_{\mathrm{n}, \mathrm{GPC}}$ 's are apparent values relative to poly(methyl methacrylate) (PMMA) standard. Surprisingly, $M_{\mathrm{n}, \mathrm{GPC}}$ and $M_{\mathrm{n} \text {,theo }}$ values matches well although hydrodynamic volume of PMMA standards are expected to be

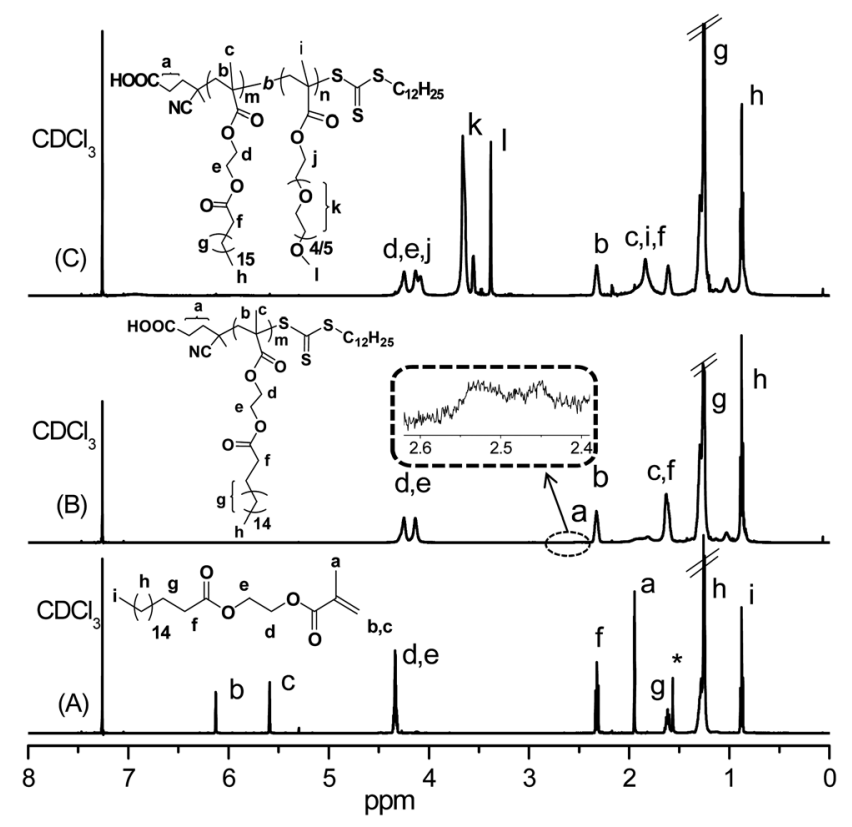

Fig. 1 The ${ }^{1} \mathrm{H}$ NMR spectra of (A) SAMA, (B) PSAMA and (C) PSAMA- $b-$ $\mathrm{PMEO}_{2} \mathrm{MA}$ in $\mathrm{CDCl}_{3}$. 
Table 1 Polymerization of FAMA's in THF at $70{ }^{\circ} \mathrm{C}^{a}$

\begin{tabular}{lllllll}
\hline Monomer & Conv. $^{b}(\%)$ & $M_{\mathrm{n}, \mathrm{GPC}}{ }^{c}\left(\mathrm{~g} \mathrm{~mol}^{-1}\right)$ & $\mathrm{PDI}^{c}$ & $M_{\mathrm{n}, \mathrm{NMR}}{ }^{d}\left(\mathrm{~g} \mathrm{~mol}^{-1}\right)$ & $M_{\mathrm{n}, \mathrm{Uv}_{-\mathrm{Vis}}}{ }^{e}\left(\mathrm{~g} \mathrm{~mol}^{-1}\right)$ & $M_{\mathrm{n}, \mathrm{theo}}^{f}\left(\mathrm{~g} \mathrm{~mol}^{-1}\right)$ \\
\hline CLAMA & 78 & 10000 & 1.13 & 13000 & 12500 & 10400 \\
CRAMA & 79 & 13100 & 1.14 & 13800 & 12800 & 13200 \\
LAMA & 73 & 14600 & 1.17 & 12500 & 15900 & 11800 \\
MAMA & 75 & 15500 & 1.19 & 14200 & 17100 & 13200 \\
PAMA & 81 & 16000 & 1.16 & 19300 & 19200 & 17200
\end{tabular}

${ }^{a}[\mathrm{FAMA}] /[\mathrm{CDP}] /[\mathrm{AIBN}]=50 / 1 / 0.2$; time $=7 \mathrm{~h} .{ }^{b}$ Determined gravimetrically based on monomer feed. ${ }^{c}$ Measured by GPC. ${ }^{d}$ Obtained from ${ }^{1} \mathrm{H}$ NMR. ${ }^{e}$ Determined by UV-Vis study. ${ }^{f} M_{\mathrm{n}, \text { theo }}=\left([\mathrm{FAMA}] /[\mathrm{CDP}] \times\right.$ molecular weight $\left(M_{\mathrm{w}}\right)$ of FAMA $\times$ conversion $)+\left(M_{\mathrm{w}}\right.$ of CDP $)$.

different compared to the compact FAMA-based polymers. Demetriou and Krasia-Christoforou also showed excellent agreement between $M_{\mathrm{n}, \mathrm{GPC}}$ and $M_{\mathrm{n}, \text { theo }}$ for the RAFT polymerization of LMA. ${ }^{17}$

The PFAMA polymers showed expected absorption for trithiocarbonate moiety at $\lambda_{\max } \sim 309 \mathrm{~nm}$, indicating retention of the CTA group during RAFT polymerization. We determined number-average molecular weight $\left(M_{\mathrm{n}, \mathrm{UV}-\mathrm{Vis}}\right)$ by this method. ${ }^{18}$ The $M_{\mathrm{n}, \mathrm{UV}-\mathrm{Vis}}$ matches nicely with the $M_{\mathrm{n}, \mathrm{GPC}}$ and $M_{\mathrm{n}, \text { theo }}$ values (Table 1).

Polymerizations kinetics of FAMAs were also studied at different monomer $(\mathrm{M})$ to CDP ratios $([\mathrm{M}] /[\mathrm{CDP}])$, while keeping constant molar ratios of $[\mathrm{CDP}] /[\mathrm{AIBN}]=5: 1$. For all the monomers, unimodal GPC refractive index traces without shoulder and tailing confirming no bimolecular terminations during the polymerization for conversions up to $\mathrm{ca}$. $87 \%$ for $[\mathrm{M}] /$ [CDP] ratios between 25 and 100 (Fig. 2A and B). Fig. 2C and D show that the $M_{\mathrm{n}, \mathrm{GPC}}$ increases linearly with the increase of monomer/CDP ratio with narrow PDI (1.10-1.34) indicating the feasibility to control the molecular weight of poly(FAMA) (PFAMA) with the alteration of $[\mathrm{M}] /[\mathrm{CDP}]$ (also see Table $\mathrm{S} 4$ and Fig. S12 of the ESI $\dagger$ ). By replacing CDP with CTP while keeping all other reaction conditions constant, we observed reasonable agreement between $M_{\mathrm{n}, \mathrm{GPC}}$ and $M_{\mathrm{n} \text {,theo }}$ values with narrow PDI and GPC RI traces without shoulder and tailing (Tables S5, ESI $\dagger$ ). Generally, CDP and CTP are excellent CTA for the preparation of well-defined methacrylate polymers, ${ }^{19}$ and the above results indicate that both CDP and CTP can be used for the controlled RAFT polymerization of FAMA.

\section{Chain extension and block copolymerization}

In the next stage, additional confirmation for the living nature of the polymerizations and possibility of block copolymer synthesis are examined. The resulting PFAMA homopolymers are used as macroCTA's for the chain extension and block copolymerization with FAMA and $\mathrm{MEO}_{2} \mathrm{MA}$, respectively, at [FAMA or $\left.\mathrm{MEO}_{2} \mathrm{MA}\right] /[$ PFAMA-macroCTA] $/[$ AIBN] $=25: 1: 0.2$ in $\mathrm{THF}$ at $70{ }^{\circ} \mathrm{C}$. The results are shown in Table 2 and Table S6 of ESI, $\dagger$ where $M_{\mathrm{n}, \mathrm{GPC}}$ values are in good agreement with the $M_{\text {n,theo }}$ values determined from conversion data. Also, unimodal RI traces of chain extended homopolymers (PFAMA- $b$-PFAMA) and block copolymers (PFAMA- $b$ - MMEO $_{2} \mathrm{MA}$ ) moved towards the higher molecular weight region with respect to the original macroCTA without any noticeable bimolecular termination products or unreacted macroCTA (Fig. 3 and S13 in ESI $\dagger$ ). Successful chain extension and block copolymerization confirmed end group retention with controlled molecular weight and narrow PDI.

The ${ }^{1} \mathrm{H}$ NMR technique was used to determine the chain-end structure and absolute molecular weights of PFAMA (Fig. 1B), PFAMA- $b$-PFAMA and PFAMA- $b$-PMEO ${ }_{2}$ MA (Fig. 1C). Various proton peaks from the main chain repeating unit are assigned on the spectra. In addition, we observed a peak at $3.20 \mathrm{ppm}$ corresponding to the $-\mathrm{S}-\mathrm{C}(=\mathrm{S})-\mathrm{S}-\mathrm{CH}_{2}-\mathrm{C}_{11} \mathrm{H}_{23}$ fragment protons and signals at 2.39-2.62 ppm from HOOC- $\mathrm{CH}_{2}-\mathrm{CH}_{2}-$ $\mathrm{C}(\mathrm{CN})\left(\mathrm{CH}_{3}\right)$ - moiety in the chain ends of the polymer. ${ }^{22}$ Comparison of the integration areas from the terminal resonance signal at $2.39-2.62 \mathrm{ppm}(4 \mathrm{H})$ and the repeating unit protons at 4.04-4.41 ppm from the side chain $-\mathrm{O}-\mathrm{CH}_{2}-\mathrm{CH}_{2}-\mathrm{O}-$ protons $(4 \mathrm{H})$ allowed calculation of the number-average molecular weight $\left(M_{\mathrm{n}, \mathrm{NMR}}\right)$ from the NMR spectroscopy (Table 1 and $\mathrm{S}^{\dagger}+$ ). The NMR spectra of the block copolymers in $\mathrm{CDCl}_{3}$ confirmed the presence of the peaks associated with each block. The integration ratios of main chain protons from $\mathrm{PMEO}_{2} \mathrm{MA}$ segment at 3.39 ppm to the CTA methylene protons at 2.39-2.62 ppm were used to calculate the degree of polymerization $\left(\mathrm{DP}_{n}\right)$ for the $\mathrm{PMEO}_{2} \mathrm{MA}$ block. The $\mathrm{DP}_{n}$ values in combination with the molecular weights of macroCTA's allowed determination of the $M_{\mathrm{n}, \mathrm{NMR}}$ of block copolymers. Good agreement between the $M_{\text {n,theo }}, M_{\mathrm{n}, \mathrm{NMR}}$, and $M_{\mathrm{n}, \mathrm{GPC}}$ suggests controlled RAFT polymerization with the polymer chain ends having the fragments of CTA as expected according to the general mechanism of the RAFT technique.

\section{Thermal properties}

Thermal degradation studies under nitrogen atmosphere using TGA studies confirmed thermal stability of PFAMA polymers up to $\mathrm{ca} .175{ }^{\circ} \mathrm{C}$ (Fig. 4A). The first stage between 175 and $245^{\circ} \mathrm{C}$ could be attributed to the decomposition of trithiocarbonate functionality in polymer chain ends. The mass loss in this region is substantially higher for PCRAMA and PCLAMA than that expected on the basis of loss of the end group alone, although in these polymers contribution from chain ends are higher compared to other PFAMA's. Above $245^{\circ} \mathrm{C}$, side-group decomposition of monomer units and residual chain degradation takes place. ${ }^{\mathbf{2 0}}$

Since ATRP made poly(lauryl methacrylate) (PLMA) showed melting point $\left(T_{\mathrm{m}}\right)$ of $-34{ }^{\circ} \mathrm{C},{ }^{9}$ thermal properties of PFAMA 

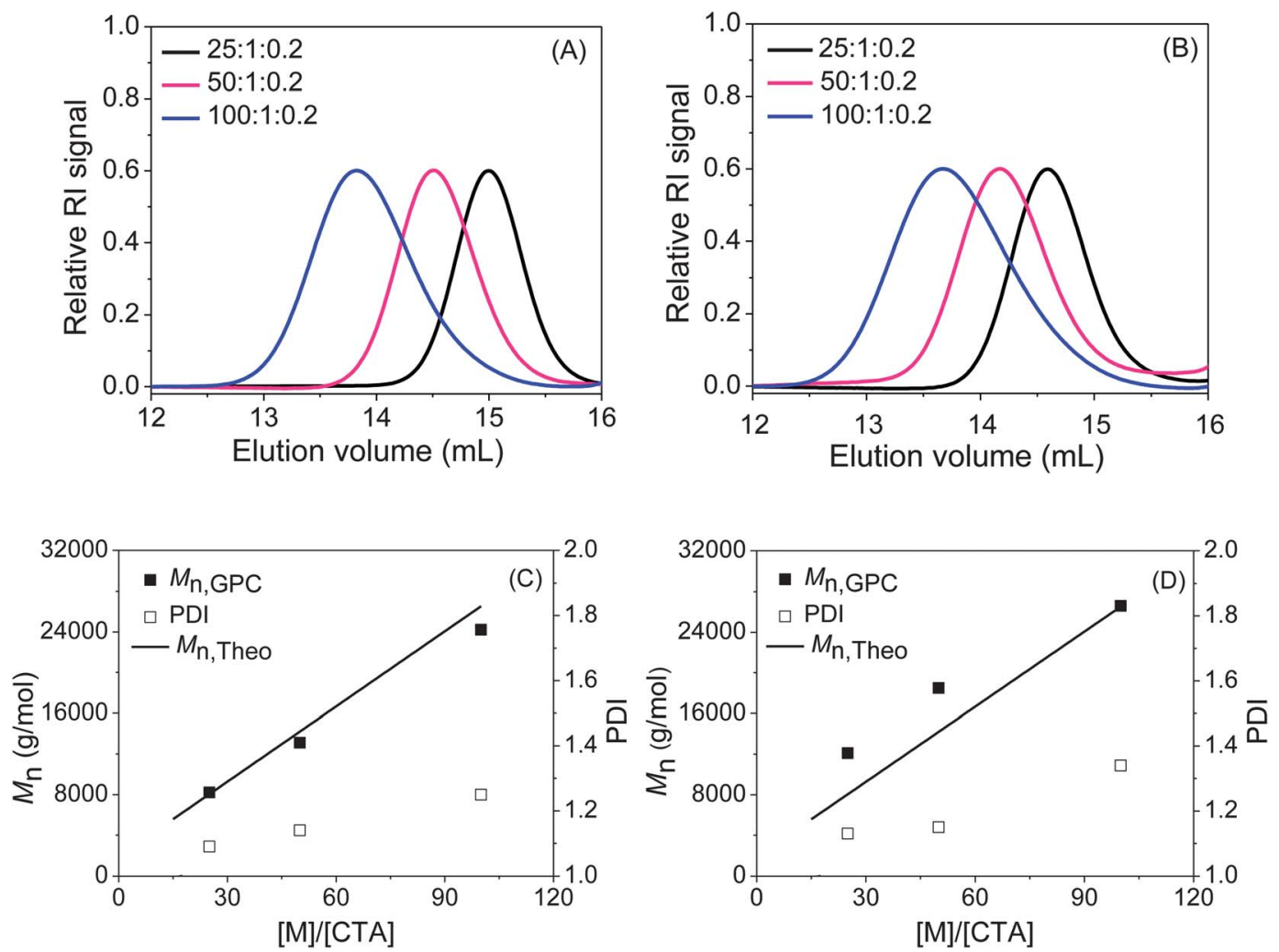

Fig. 2 GPC RI traces of PCRAMA (A) and PSAMA (B) obtained at different [M]/[CDP] ratios, and dependence of $M_{n}$ and PDI on [M]/[CDP] ratio for the RAFT polymerization of CRAMA (C) and SAMA (D) in THF at $70^{\circ} \mathrm{C}$.

Table 2 Block copolymerization with PCRAMA, PMAMA and PSAMA macroCTAs at $70{ }^{\circ} \mathrm{C}$ in $\mathrm{THF}^{\mathrm{a}}$

\begin{tabular}{|c|c|c|c|c|c|}
\hline Block copolymers & Macro CTA & Conv. $^{b}(\%)$ & $M_{\mathrm{n}, \mathrm{GPC}}{ }^{c}\left(\mathrm{~g} \mathrm{~mol}^{-1}\right)$ & $\mathrm{PDI}^{c}$ & $M_{\mathrm{n}, \text { theo }}{ }^{d}\left(\mathrm{~g} \mathrm{~mol}^{-1}\right)$ \\
\hline PCRAMA- $b$-PCRAMA & PCRAMA & 62 & 14400 & 1.15 & 12600 \\
\hline PCRAMA- $b-\mathrm{PMEO}_{2} \mathrm{MA}$ & PCRAMA & 65 & 14700 & 1.16 & 13100 \\
\hline PMAMA- $b-\mathrm{PMEO}_{2} \mathrm{MA}$ & PMAMA & 48 & 13900 & 1.15 & 14300 \\
\hline PSAMA- $b$-PSAMA & PSAMA & 91 & 18100 & 1.22 & 21400 \\
\hline PSAMA- $b-\mathrm{PMEO}_{2} \mathrm{MA}$ & PSAMA & 55 & 16000 & 1.17 & 16200 \\
\hline
\end{tabular}

${ }^{a}$ Molar ratio of $[\mathrm{M}] /[$ macroCTA $] /[$ AIBN $]=25 / 1 / 0.2$, time $=7$ h. ${ }^{b}$ Determined by gravimetric analysis. ${ }^{c}$ Measured by GPC. ${ }^{d}$ Theoretical $M_{\mathrm{n}}$.

homopolymers were examined by DSC. Fig. 4B shows DSC thermograms of PFAMA homopolymers at $10^{\circ} \mathrm{C} \mathrm{min}^{-1}$ heating rate under nitrogen atmosphere, demonstrating $T_{\mathrm{m}}$ of approximately 12,33 , and $47{ }^{\circ} \mathrm{C}$ for PMAMA, PPAMA and PSAMA, respectively. Similar increase of $T_{\mathrm{m}}$ with increasing alkyl chain lengths in the fatty acid containing polymers are reported, where polymers were prepared using ATRP of fatty acid based methacrylate monomers prepared from the reaction of methacryloyl chloride and fatty alcohols in diethyl ether. ${ }^{9}$ Increasing side chain crystallization is expected with the increasing alkyl chain lengths on the basis of symmetry and regularity even in the absence of strong intermolecular forces. ${ }^{21}$ Interestingly, we did not observe any $T_{\mathrm{m}}$ for PLAMA although PLMA from ATRP and double-grafted cylindrical brushes with PLMA as the side chains ${ }^{22}$ showed $T_{\mathrm{m}}$. This could be due to the presence of extra $-\mathrm{CH}_{2}-\mathrm{CH}_{2}-\mathrm{O}-$ flexible unit in PLAMA compared to PLMA, which prevent crystallization of side chains. Note that we could not determine the degree of crystallinity from DSC study because of unavailable heat of fusion data for the perfect crystal.

\section{Crystalline morphologies of polymers}

Crystalline structure was further examined by small-angle Xray scattering (SAXS, Fig. 5A) and wide-angle X-ray scattering (WAXS, Fig. 5B) techniques. The SAXS profile of PSAMA $(2 \theta=$ $\left.2.52^{\circ}\right)$ and PPAMA $\left(2 \theta=2.62^{\circ}\right)$ show sharp peak (with multiplicity) indicating well-ordered structure formation. However, the scattering peak for PMAMA $\left(2 \theta=2.70^{\circ}\right)$ and PLAMA $(2 \theta=$ $2.89^{\circ}$ ) is very broad. A second scattering peak at $2 \theta=5.04^{\circ}$ and $5.24^{\circ}$ for respectively PSAMA and PPAMA were observed. These $2 \theta$ values are exactly double than the first $2 \theta$ peaks, 

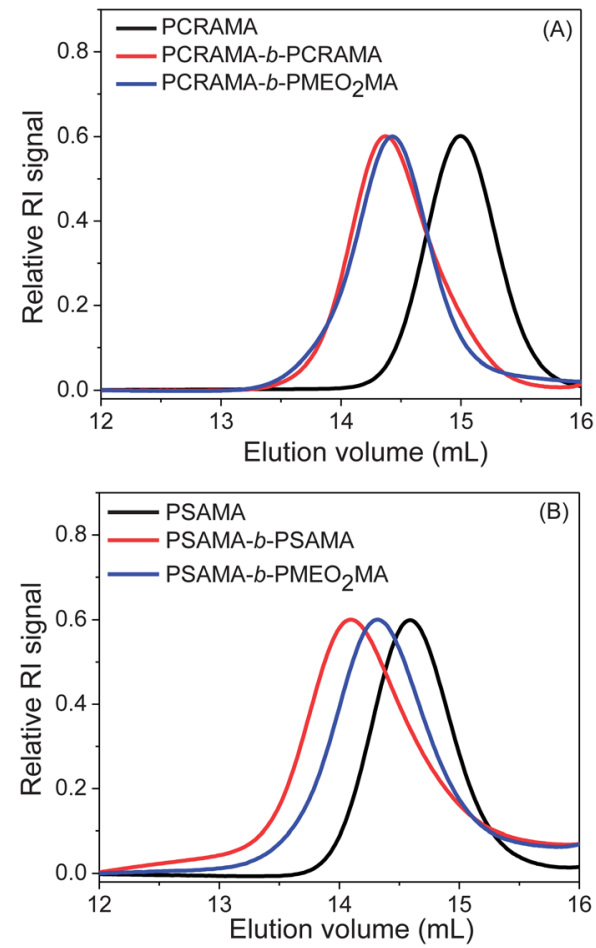

Fig. 3 GPC RI traces of the (A) PCRAMA-macroCTA, chain extended PCRAMA- $b$-PCRAMA and block copolymer PCRAMA- $b-\mathrm{PMEO}_{2} \mathrm{MA}$; (B) PSAMAmacroCTA, chain extended PSAMA-b-PSAMA and block copolymer PSAMA- $b$ $\mathrm{PMEO}_{2} \mathrm{MA}$.
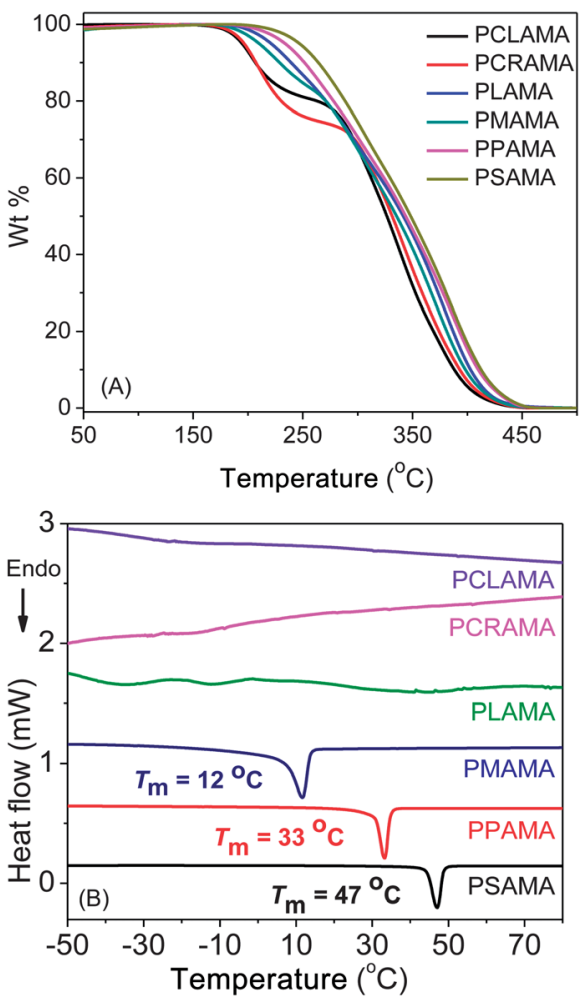

Fig. 4 TGA thermograms ( $A$ ) and DSC curves (B) of various side chain fatty acidcontaining polymers under $\mathrm{N}_{2}$ at a heating rate of $10{ }^{\circ} \mathrm{C} \mathrm{min}-1$. indicating lipid lamellar structure. ${ }^{23} \mathrm{~A}$ crystalline phase of the lamella may be formed due to the interactions of the alkyl chains in the side chain. As expected, the long spacing $(d)^{23}$ decreases with decreasing chain length of the fatty acid and we have determined $d$ values of 35.0, 33.7, 32.7 and $30.4 \AA$ for PSAMA to PPAMA, PMAMA and PLAMA, respectively. A bilayer crystalline structure with a repeat distance of $40.8 \AA$ is reported for stearic acid. ${ }^{24}$ The $d=35.0$ Å for PSAMA indicates formation of different crystal structure than for only stearic acid due to the main chain methacrylate backbone with flexible $-\mathrm{CH}_{2}-\mathrm{CH}_{2}-\mathrm{O}-$ side chain units. However, above SAXS results provided lamellar structure for PSAMA, PPAMA, PMAMA and PLAMA. ${ }^{25}$

The effect of fatty acid chain length on crystallinity is also seen from the WAXD plots in Fig. 5B. The peaks around $2 \theta=$ $18.9^{\circ}(d=4.68 \AA)$ in the WAXD plot in Fig. 5B for PSAMA, PPAMA, PMAMA and PLAMA indicate the amorphous halo. ${ }^{26}$ PSAMA and PPAMA show a sharp peak $\left(2 \theta=21.47^{\circ}, d=4.13 \AA\right)$ in addition to the broad peak, where the sharp peak is due to the crystallinity in those two polymers. Because of higher percentage of crystallinity in PSAMA as noticed in WAXS, the $d$ spacing between two lamellas is distinct as observed from SAXS. Increasing side-chain length helps crystalline domain formation due to the hydrophobic interaction among the large alkyl chains. ${ }^{21}$ Also, polarized optical microscopy images of PSAMA and PPAMA (Fig. 6) showed a birefringent texture distinctive of semicrystalline linear polymer chains, which melts and become isotropic when heated above their $T_{\mathrm{m}}{ }^{27}$
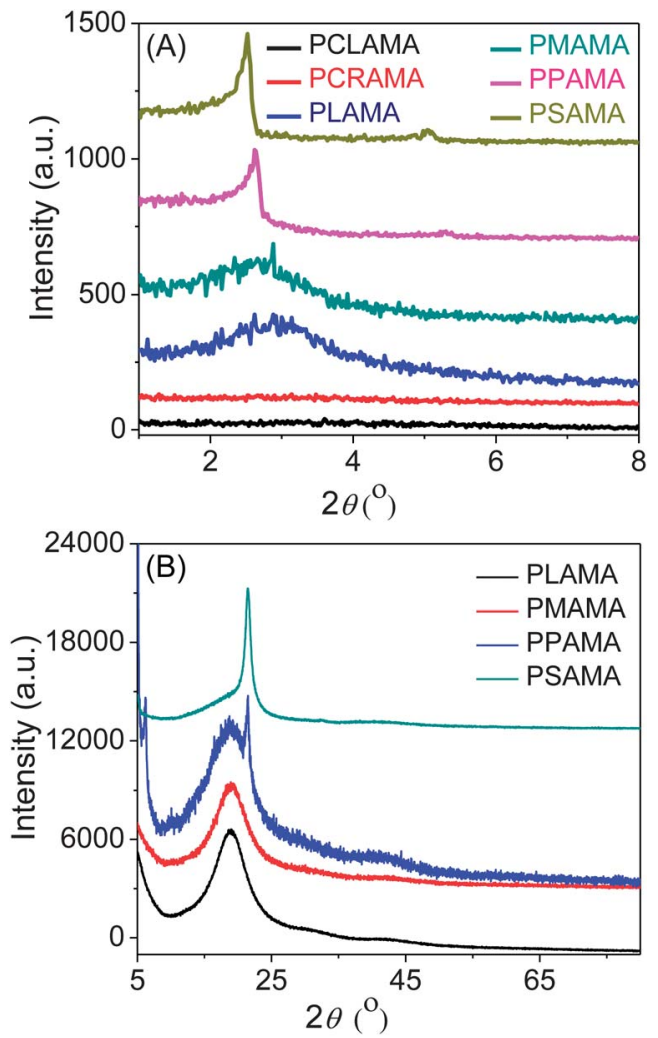

Fig. 5 (A) SAXS and (B) WAXS patterns of various PFAMA's. 

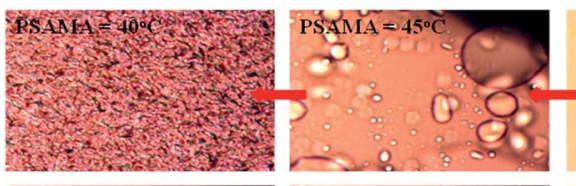

PSAMA $=60^{\circ} \mathrm{C}$

PPAMA $=30^{\circ} \mathrm{C}$

PPAMA $=40^{\circ} \mathrm{C}$
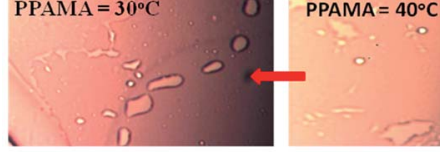

PCRAMA $=30^{\circ} \mathrm{C}$

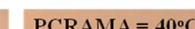

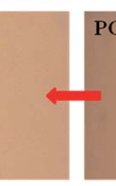

Fig. 6 Polarized optical microscopy images of PSAMA (top row), PPAMA (middle row) and PCRAMA (bottom row) at different temperatures.

\section{Conclusion}

In summary, we have demonstrated the RAFT polymerization of fatty acid containing methacrylate monomers to prepare fatty acid-based polymers with pre-determined molecular weights and narrow PDI. The chain extension from PFAMA macroCTAs for the preparation of block copolymers has also been explored and PFAMA- $b$ - $\mathrm{PMEO}_{2} \mathrm{MA}$ has been prepared. By changing the alkyl chain length in the fatty acid, it is possible to obtain materials with different physical properties such as crystallinity and solubility. We are currently extending our study to the design of fatty acid containing amphiphilic random copolymers as unimer micelles. ${ }^{28}$ The self-assembly potential of the well-defined fatty acid derived polymers (both random and block copolymers) can provide the means to the construction of tailored materials from renewable resources with unique properties for various applications, such as controlled drug release and biocompatible materials.

\section{Acknowledgements}

We thank Department of Science and Technology (DST), Government of India, India, for financial support [Project no. SR/S1/OC-51/2010]. Binoy Maiti acknowledges Council of Scientific and Industrial Research (CSIR), Government of India, India, for the junior research fellowship.

\section{Notes and references}

1 (a) C. K. Williams and M. A. Hillmyer, Polym. Rev., 2008, 48, 1-10; (b) K. Yao and C. Tang, Macromolecules, 2013, 46, 16891712.

2 U. Biermann, W. Friedt, S. Lang, W. Lühs, G. Machmüller, J. O. Metzger, M. Rüsch gen Klaas, H. J. Schäfer and M. P. Schneider, Angew. Chem., Int. Ed., 2000, 39, 22062224.

3 M. A. R. Meier, J. O. Metzger and U. S. Schubert, Chem. Soc. Rev., 2007, 36, 1788-1802.
4 F. S. Günera, Y. Yagci and A. T. Erciyes, Prog. Polym. Sci., 2006, 31, 633-670.

5 L. Maisonneuve, T. Lebarbé, E. Grau and H. Cramail, Polym. Chem., 2013, 4, 5472-5517.

6 E. Hempel, H. Huth and M. Beiner, Thermochim. Acta, 2003, 403, 105-114.

7 (a) W. Xu, X. Zhu, Z. Cheng and J. Chen, J. Appl. Polym. Sci., 2003, 90, 1117-1125; (b) V. Raghunadh, D. Baskaran and S. Sivaram, Polymer, 2004, 45, 3149-3155; (c) D. P. Chatterjee and B. M. Mandal, Polymer, 2006, 47, 1812-1819.

8 W. A. Braunecker and K. Matyjaszewski, Prog. Polym. Sci., 2007, 32, 93-146.

9 G. Çayli and M. A. R. Meier, Eur. J. Lipid Sci. Technol., 2008, 110, 853-859.

10 (a) G. Moad, E. Rizzardo and S. H. Thang, Aust. J. Chem., 2006, 59, 669-692; (b) H. Gemici, T. M. Legge, M. Whittaker, M. J. Monteiro and S. Perrier, J. Polym. Sci., Part A: Polym. Chem., 2007, 45, 2334-2340; (c) J. N. Cambre, D. Roy, S. R. Gondi and B. S. Sumerlin, J. Am. Chem. Soc., 2007, 129, 10348-10349.

11 C. Boyer, V. Bulmus, T. P. Davis, V. Ladmiral, J. Liu and S. Perrier, Chem. Rev., 2009, 109, 5402-5436.

12 J. Dziczkowski and M. D. Soucek, J. Coat. Technol. Res., 2010, 7, 587-602.

13 S. Wang, S. V. Kesava, E. D. Gomez and M. L. Robertson, Macromolecules, 2013, 46, 7202-7212.

14 (a) D. L. Patton, M. Mullings, T. Fulghum and R. C. Advincula, Macromolecules, 2005, 38, 8597-8602; (b) D. Boschmann and P. Vana, Macromolecules, 2007, 40, 2683-2693; (c) T. Krivorotova, E. Udrénaite, D. Gromadzki and R. Makuška, Chemija, 2010, 21, 63-71.

15 G. Moad, Y. K. Chong, A. Postma, E. Rizzardo and S. H. Thang, Polymer, 2005, 46, 8458-8468.

16 C. J. Ferguson, R. J. Hughes, B. T. T. Pham, B. S. Hawkett, R. G. Gilbert, A. K. Serelis and C. H. Such, Macromolecules, 2002, 35, 9243-9245.

17 M. Demetriou and T. Krasia-Christoforou, J. Polym. Sci., Part A: Polym. Chem., 2008, 46, 5442-5451.

18 S. Kumar, S. G. Roy and P. De, Polym. Chem., 2012, 3, 12391248.

19 (a) K. Bauri, S. G. Roy, S. Pant and P. De, Langmuir, 2013, 29, 2764-2774; (b) S. G. Roy, R. Acharya, U. Chatterji and P. De, Polym. Chem., 2012, 4, 1141-1152.

20 K. Bauri, S. Pant, S. G. Roy and P. De, Polym. Chem., 2013, 4, 4052-4060.

21 S. Zhou, Y. Zhao, Y. Cai, Y. Zhou, D. Wang, C. C. Han and D. Xu, Polymer, 2004, 45, 6261-6268.

$22 \mathrm{Y}$. Xu, H. Becker, J. Yuan, M. Burkhardt, Y. Zhang, A. Walther, S. Bolisetty, M. Ballauff and A. H. E. Müller, Macromol. Chem. Phys., 2007, 208, 1666-1675.

23 T. Maruyama, M. Nakajima, S. Ichikawa, Y. Sano, H. Nabetani, S. Furusaki and M. Seki, Biosci., Biotechnol., Biochem., 2001, 65, 1003-1006.

24 S. Zhu, M. Heppenstall-Butler, M. F. Butler, P. D. A. Pudney, D. Ferdinando and K. J. Mutch, J. Phys. Chem. B, 2005, 109, 11753-11761. 
25 X. Zeng and G. Ungar, Polymer, 1998, 39, 45234533.

26 K. Jokela, A. Väänänen, M. Torkkeli, P. Starck, R. Serimaa, B. Löfgren and J. Seppälä, J. Polym. Sci., Part B: Polym. Phys., 2001, 39, 1860-1875.
27 E. Espinosa, B. Charleux, F. D'Agosto, C. Boisson, R. Tripathy, R. Faust and C. Soulié-Ziakovic, Macromolecules, 2013, 46, 3417-3424.

28 S. Bhatia, A. Mohr, D. Mathur, V. S. Parmar, R. Haag and A. K. Prasad, Biomacromolecules, 2011, 12, 3487-3498. 